\title{
Evidence of Pragmatic Impairments in Speech and Proverb Interpretation in Schizophrenia
}

\author{
Marc H. Haas - Steven A. Chance - David F. Cram • \\ Tim J. Crow • Aslan Luc • Sarah Hage
}

Published online: 23 April 2014

C Springer Science+Business Media New York 2014

\begin{abstract}
Schizophrenia has been suggested to involve linguistic pragmatic deficits. In this study, two aspects of pragmatic ability were assessed; comprehension and production. Drawing on relevance theory and Gricean implicatures to assess shared attention and interpretation in a linguistic context, discourse samples and proverb interpretation were transcribed from recorded interviews with patients with schizophrenia and control subjects. The productive aspect of implicatures was assessed by quantifying the use of 'connectors' in discourse. Receptive aspects were assessed by scoring interpretations of four common proverbs. Statistically significant effects were found: patients with schizophrenia used connectors less than controls as well as performing worse in proverb comprehension. Positive correlations between connectors and proverb interpretation in all subjects suggested an underlying pragmatic root for both productive and receptive aspects. The relative number of connectors (as a percentage of words used) provided a better index of pragmatic ability than total number
\end{abstract}

Electronic supplementary material The online version of this article (doi:10.1007/s10936-014-9298-2) contains supplementary material, which is available to authorized users.

M. H. Haas · D. F. Cram

Department of Linguistics, University of Oxford, Oxford, UK

S. A. Chance $\cdot$ S. Hage

Nuffield Department of Clinical Neurosciences, John Radcliffe Hospital,

University of Oxford, Oxford, UK

T. J. Crow · A. Luc

University Department of Psychiatry, Warneford Hospital, Oxford, UK

M. H. Haas

Present address:

Department of Philosophy, ETH Zürich, Zürich, Switzerland

M. H. Haas $(\bowtie)$

Eidgenössische Technische Hochschule Zürich, Professur für Philosophie, IFW,

Haldeneggsteig 4, 8092 Zürich, Switzerland

e-mail: mahaas@student.ethz.ch 
because total output appeared to be influenced by additional factors such as IQ. Deficits were found in the use of connectors and in proverb interpretation even when controlling for verbal IQ, suggesting that pragmatic aspects of language are particularly vulnerable in schizophrenia compared with other verbal abilities.

Keywords Schizophrenia - Pragmatics - Linguistics - Relevance theory - Discourse · Proverbs

\section{Introduction}

Evidence suggests that schizophrenia does not represent a global breakdown of language but rather affects specific components of linguistic processing. For example, semantic aspects of language are more disrupted than phonological aspects (Bokat and Goldberg 2003). Much work on schizophrenia has focused on semantics, and patients have been shown to have semantic memory networks that are less organised than those of control subjects (Paulsen and Romeroa Ramon 1996; Rossell 2006). However, while deficits at the pragmatic level are indicated by several studies and aspects of schizophrenic symptoms, explicit examination of pragmatics in schizophrenic language is relatively under-investigated. It appears that several psychiatric disorders such as schizophrenia (Brüne and Bodenstein 2005; Mitchley et al. 1998), autism (Happé 1993), or high levels of paranoia (Cram and Hedley 2005) have a strong tendency to involve impairment at the pragmatic level (Cummings 2009).

Many authors (Abu-Akel 1999; Brüne 2005; Corcoran et al. 1995; Corcoran 2000; Corcoran and Frith 2003; Frith and Corcoran 1996; Harrington et al. 2005; Langdon et al. 2002; Pickup and Frith 2001) claim that patients with schizophrenia have an impaired Theory of Mind (ToM), that is, they often lack the ability to represent for themselves their interlocutor's state of mind, both emotional and intellectual. This view has been supported by meta-analyses (Sprong et al. 2007) which have shown that the effect sizes for overall ToM performance and the individual tasks are large (Bora et al. 2009). The close links between pragmatic competence and ToM suggest that measures of communicative pragmatics may be sensitive to, and provide insight in to, schizophrenic disorder. Poor social cognition and ToM skills are detected not only in schizophrenic patients but also in their non-psychotic relatives suggesting that a lack of ToM ability may be a genetically determined trait in schizophrenia (Anselmetti et al. 2009). Neuroanatomical studies have related deficit of ToM ability to brain abnormalities in schizophrenia both structural and functional, supporting a biological basis for impaired social skills and maladaptive interpersonal functioning in schizophrenia (Abu-Akel 2003).

According to relevance theory (Sperber and Wilson 1995, 2002), one of the key enabling features of successful communication is the ability to recognise the interlocutor's intentions. For example, utterances whose meaning cannot be derived directly from their semantic content, like metaphors or ironical statements, require that the hearer understands the context in which the literally non-sensical utterances are produced. Irony (saying one thing and meaning the opposite) is a clear example of this - one cannot understand irony without awareness of someone's intention to be ironic; similarly, without an ability to determine an interlocutor's state of mind one is unable to interpret metaphors. Such deficits have been reported in autism (Happé 1993). According to relevance theory, the ability to recognise an intention is part of ostension (Sperber and Wilson 1995), the awareness that intersubjective knowledge is shared and actively used in conversation, as well as relative to a given situation or context ("Mary knows that Paul knows that she knows": see further explanation 
in method section, below). Not only does this concept apply to comprehension (interpreting a non-literal utterance), but it also applies to productive aspects (producing non-literal utterances).

Drawing on insights derived from relevance theory, the present study was designed to examine both comprehension and production aspects of communication in subjects with schizophrenia: In order to test the ability of patients to comprehend pragmatic information, their interpretation of proverbs and idioms was examined and quantified. This method is widely used in the assessment of schizophrenia (Brüne 2005; Barth and Küfferle 2001; Holm-Hadulla 1991) although it has been criticized (Andreasen 1977) as the reliability of the assessment procedures has been questioned. However, the results of our study as well as other relatively recent ones (e.g., Brüne and Bodenstein 2005) suggest that careful refinement of the selection of test components provides greater confidence in the procedure, thus allowing us to sustain the hypothesis that schizophrenia impairs pragmatic ability, and that pragmatic ability may be an autonomous cognitive function.

In order to determine the ability of the schizophrenic patients to use their pragmatic skills in speech production, we assessed implicatures, in the sense of Grice (1975). We did so by looking at the way patients understood pragmatic connectors such as but, and, so, if, therefore, etc., whose interpretation necessarily involves a pragmatic dimension involving implicature (Huang 2006). Crucially, for our present purposes, an implicature is an element of meaning which is contextually triggered rather than solely derived from the semantic content of the component words of the utterance.

In summary, the present study investigated two aspects of pragmatic ability in order to assess the relationship between pragmatic processes which are found in both comprehension and production. In addition, the relationship with other neuropsychological measures enabled comment on the degree to which pragmatic deficits reflect impairment of the broader cognitive profile or, alternatively, indicate more specific pragmatic dysfunction. The hypothesis was that if the pragmatic ability for comprehension is similar to the pragmatic ability for production then these should show a similar pattern of variation and probable deficit in schizophrenia.

\section{Method}

\section{Subjects}

The study has been conducted on a total of 22 subjects; 15 of them were diagnosed with schizophrenia and constituted the clinical group, while the remaining seven constituted the control group.

In the clinical group, all patient diagnoses were confirmed by the structured clinical interview for DSM-IV Disorders (SCID) and all were taking anti-psychotic medication. All patients were naïve to the aim of the research. Patients' mean age at onset of disorder was 23.47 years (18-45 years of age, SD 5.72) and mean duration of illness was 10.13 years (0-29 years, SD 8.97).

Controls consisted of seven persons, who were also blind to the object of the interviews. Control subjects were recruited via general practitioners. Exclusion criteria were history of substance abuse, brain injury, epilepsy or other neuropsychiatric disorder e.g., mental retardation, pervasive developmental disorder. In addition controls had no psychiatric history in first-degree relatives, and no medication other than oral contraceptives.

The mean age of all 22 subjects at the time of testing was 33.6 years (18-45 years old, SD 8.2) and controls were 28.0 years (19-33 years old, SD 4.9). 
Given the resource constraints available for this study a lower number of control subjects were adequate to demonstrate the range and differences in measures-pilot assessments showed that much lower variation would be detected in the control data.

Principles of Assessment

Our study focuses on both interpretation and production of context-bound utterances. The method we have devised for this purpose is built on the concepts of ostension for the interpretation aspect and implicatures for the production aspect. We are also explaining in detail the method used for the quantification of pragmatic interpretation and production as well as the statistical method that we used.

\section{Interpretation (Ostension)}

Consider the following example taken from Cummings (2009):

(1) Paul: Do you want to go out tonight?

Mary: I'm depressed.

In this case, Mary's answer could mean both yes or no: she could want to be cheered up by a night out or on the contrary she could signify her desire to stay at home and rest. However, she would not produce this utterance if she was not certain that Paul will understand it (one assumption in the relevance theory model being that each interlocutor presumes that an utterance necessarily carries the assumption of its own relevance, because otherwise it would not be uttered). Not only does Mary know that Paul knows what she means, but she also knows that he knows that she knows. These complicated intersubjective assumptions constitute the core of the notion of ostension. It is believed that they constitute a good basis for the observation of ToM in action (Brüne 2005; Brüne and Bodenstein 2005; Sperber and Wilson 1995, 2002).

Because Mary's utterance in (1) does not contain any non-literal aspect, it is Paul's contextual inference of her state of mind that allows him to decide whether "I'm depressed", with its connotation of sadness, should be interpreted as meaning either yes or no. As in the case of personal idioms (Hopper et al. 1981), such utterances whose meaning cannot be derived straightforwardly from their component words require contextual information, which depends on who is uttering it. In such cases, the contextual information is composed to a large extent, perhaps exclusively, of the inferred mental state of the interlocutor, who must be understood to have a particular intention (in the case of particular idioms, it could be making a reference to a private joke for example). If a patient with schizophrenia does not understand that the interviewer intends to produce context-dependent utterances to some level, then the patient will interpret the interviewer's utterance literally. It is by closely examining the degree to which the patients can comprehend a non-literal string of words that their pragmatic abilities can be assessed and quantified.

\section{Production (Implicatures)}

Consider the following utterances:

(2) I went to the shop and bought a gun.

(3) I bought a gun and went to the shop.

Although these two utterances are logically equivalent from a narrowly truth-functional point of view, they have radically different interpretations in context: in (2), the most plausible 
scenario is that I bought the gun at the shop, which can then be taken to be a gunsmith's. In (3), it is most likely that I bought a gun in order to rob the shop. Since the two parts of each utterance are similar (I bought a gun/I went to the shop), it means that a specific interpretation is triggered by the word and. It can be argued that in the first case it is causative (I went to the shop in order to buy a gun) while in the second one it is only denoting a temporal succession, because I didn't buy a gun in order to go to the shop. The difference between these two instances of and is pragmatic in essence: in these and similar utterances, the speech context determines what reading of words like and is correct.

\section{Procedure}

The primary material for this research was taken from a series of partially transcribed interviews of psychiatric patients with schizophrenia, and a group of control comparison subjects recruited as part of UK MRC funded research project. The interviews generally lasted between $15 \mathrm{~min}$ and half an hour, and were conducted within the last 5-8 years in the Warneford Psychiatric Hospital in Oxford.

In addition to the SCID interview subjects were also interviewed for the modified Adult Personal Data Inventory (APDI) to clarify educational attainment and completed a Modified Wechsler Adult Intelligence Scale (WAIS-III) test to provide IQ measures (described below). The discourse samples were recorded using digital audio equipment in a quiet interview room. The sample was drawn from responses to a series of open-ended questions designed to elicit a degree of thought and opinion that would encourage some free expression. As a result of the open-ended nature of the discourse the interview time and length of speech samples was variable. For the assessment of the use of connectors, responses to a set of three questions were used as well as the speech output during the response to the proverb task. This generated sufficient speech for analysis. The total number of words per subject varied from 227 to 1,154 and the range was similar for controls $(320-1,154)$ and patients $(227-1,133)$, although the patients generated fewer words on average (see "Results" section). The three initial discourse questions are given below. During each response the participant may be prompted once (as shown) to encourage a complete response.

i) Can you tell me about the area where you live and what it is like there?

Prompt: Is there anything else you want to say about that?

ii) What do you think about the royal family?

Prompt: Is there anything else you want to say about that?

iii) Can you tell me about an animal that you especially like or an animal that you especially dislike and why you feel that way about it?

Prompt: Is there anything else you want to say about that?

Following the discourse questions, the receptive task required interpretation of four proverbs which were requested in the following manner (all subjects were asked to interpret the same set of proverbs):

I would like to ask you about some proverbs and what their meaning might be.

What do you think is the meaning of "many hands make light work"?

"The grass is always greener on the other side"?

"Don't judge a book by its cover"?

"All that glitters is not gold"

All discourse samples were transcribed by listening to the audio recordings after the interviews. All words generated by the participant, including repetitions, were transcribed. Sub- 
stantial pauses, discontinuities, 'um', 'er' and other expressions were also transcribed in a systematic manner to aid assessment (a set of established study transcription conventions were followed and are summarised in appendix 1, below).

Pragmatic Language Assessments

In this section we are discussing the method used for the quantification of both proverb interpretation and pragmatic word production.

Proverb Interpretation

The quantification of the proverb task (comprehension) was done following Barth and Küfferle's (Barth and Küfferle (2001)) scale of measure:

\begin{tabular}{lll}
\hline Type I & Meaningful and abstract & 14 Points \\
Type II & Meaningful and partly concretistic & 10 Points \\
Type III & Meaningful and concretistic & 6 Points \\
Type IV & Meaningless and concretistic & 2 Points \\
Type V & Meaningless and abstract & 0 Point \\
\hline
\end{tabular}

The distinctions may be illustrated with an interpretation of the proverb "When the cat's away, the mice will play" (taken from Barth and Küfferle 2001):

Type I If there is no control person, one can do as one wishes.

Type II If no one is there to watch, the mice can do what they want. Or: If the cat's away, one can do what they want.

Type III Cats eat mice. Thus, mice can only party when the cat has gone.

Type IV When cats and mice are away, the house is fully empty.

Type V When no one is there, one can do everything on one's own.

Pragmatic Word Production

Huang's (2006) list of pragmatic connectors was used: thus, so, therefore, because, then, when, but, since, actually, also, anyway, some, barely, besides, however, only, even, though, too, yet, except,rather, despite. Of course, these do not necessarily trigger an implicature: a word like since for example has two meanings: when it is used as a temporal connector as in "since 1886", it is not an implicature and has a literal meaning. However, when used as a discourse connector as in the following example, an implicature is generated:

(4) Since you're sick, you will stay home.

Conjunctions such as "and so", "even though", "rather than", "but also" are quite frequent. They were counted according to their implied meaning, therefore "but also" counted as two occurrences, as it means both "in contrast" and "in addition", but "even though" or "rather than" for instance were counted as one occurrence, as they only carry the meaning "despite". The total number of connector words was then compared to the total number of words in the interview, and a percentage was calculated: (connectors/total) $\times 100$. 
For the assessment of discourse and proverbs the assessor (Marc Haas) was blind to diagnosis. Although clues to diagnosis were occasionally present in the content of the discourse and discourse length was lower on average in schizophrenia, it was beneficial for blinding that the range of discourse lengths was similar across the diagnostic groups.

\section{Results}

The results show that controls and patients with schizophrenia differed substantially on the two main variables: number of pragmatic connectors (here simply called "connectors") and proverb interpretation ("proverbs"), as well as on the relative number of connectors ("percentage connectors" $=($ number of connectors/total number of words $) \times 100)$. Because of the restricted number of controls and patients, the standard deviations for most of these measures were quite high.

\section{Statistical Analysis}

Age, Education, verbal IQ (vIQ) and full scale IQ all satisfied the requirements for equality of variance tested by Levene's test. Although the mean age of patients was slightly higher, age was not significantly different between groups $\mathrm{t}=-1.66$, df $20, p=0.11$. There was a non-significant trend for controls to have spent more years in education than patients $(\mathrm{t}=1.97$, df $16, p=0.07)$, although data was unavailable for two control subjects. Controls had significantly higher verbal IQ (control mean: 27.6, SD 5.2, patient mean: 21.8, SD 6.5) $(\mathrm{t}=3.24$, df $18, p<0.01)$ and full scale IQ (control mean: 129.3 SD 18.1, patient mean: 103.8, SD 20.7) $(\mathrm{t}=3.86$, df $18, p<0.01)$ scores.

As full scale IQ and verbal IQ are highly correlated (Pearson's $r=0.96, p<0.01$ ) it was decided that verbal IQ was the most relevant measure to include as a covariate in subsequent analyses of variance (ANOVAs). Education was not included due to missing values. However, post-hoc analyses of covariance (ANCOVAs) were also performed to consider the effect of education for the subjects available and these tests indicated that education was not a significant covariate for any of the variables. Therefore, education is not reported further below.

All of the measured variables passed Levene's test for equality of variance between diagnostic groups except for the proverb score as reported below. The measured variables: total words, connectors (raw total number and as a percentage of total words) and the proverb scores were analysed with $t$ tests and post-hoc analyses of covariance (ANCOVAs). Although it is desirable to analyze data of this kind using multivariate, analyses the sample size, with some missing values for education, was sufficiently small that it was felt the erosion of degrees of freedom with additional variables would have a deleterious effect on the analysis. Relationships between these variables and other demographic details were then further studied by correlation analyses. Pearson's $r$ is reported for correlations using more than 10 values, while Spearman's rho is reported for smaller samples as Spearman's test is more robust to low sample size.

Total Words

There was a trend for control subjects to produce a greater number of words than patients in response to the questions included in this study (see Table 3 for mean values) (independent samples $t$ test, $\mathrm{t}=1.97$, df $20, p=0.06$ ). This effect appeared to be partlyinfluenced 
Table 1 Mean values

\begin{tabular}{|c|c|c|c|c|}
\hline ID & Connectors & $\begin{array}{l}\text { Total } \\
\text { words }\end{array}$ & $\begin{array}{l}\text { Percent } \\
\text { connectors }\end{array}$ & $\begin{array}{l}\text { Proverb } \\
\text { score }\end{array}$ \\
\hline
\end{tabular}

\begin{tabular}{|c|c|c|c|c|c|}
\hline & \multicolumn{5}{|l|}{ Controls } \\
\hline & CF050 & 25 & 320 & 7.81 & 13.00 \\
\hline & CF053 & 46 & 690 & 6.67 & 12.00 \\
\hline & CF055 & 37 & 517 & 7.16 & 12.00 \\
\hline & CF057 & 45 & 786 & 5.73 & 12.00 \\
\hline & CF058 & 44 & 669 & 6.58 & 13.00 \\
\hline & CF059 & 40 & 853 & 4.69 & 11.00 \\
\hline & CF060 & 58 & 1,154 & 5.03 & 11.00 \\
\hline & Mean & 42.14 & 712.71 & 6.24 & 12.00 \\
\hline & $\mathrm{SD}$ & 10.02 & 262.91 & 1.14 & 0.82 \\
\hline & \multicolumn{5}{|c|}{ Schizophrenia } \\
\hline & CF054 & 7 & 227 & 3.08 & 7.33 \\
\hline & CF067 & 8 & 291 & 2.75 & 6.67 \\
\hline & CF072 & 43 & 801 & 5.37 & 8.00 \\
\hline & CF074 & 34 & 659 & 5.16 & 6.50 \\
\hline & CF088 & 6 & 214 & 2.80 & 3.75 \\
\hline & CF098 & 7 & 365 & 1.92 & 3.00 \\
\hline & CF099 & 4 & 289 & 1.38 & 0.75 \\
\hline & CF100 & 7 & 246 & 2.85 & 0.50 \\
\hline & CF105 & 28 & 612 & 4.58 & 10.00 \\
\hline & CF106 & 15 & 350 & 4.29 & 6.50 \\
\hline \multirow{7}{*}{$\begin{array}{l}\text { Connectors: number of } \\
\text { connectors in the discourse } \\
\text { sample; Total words: total } \\
\text { number of words in the discourse } \\
\text { sample. Percent connectors: } \\
\text { percentage of connectors relative } \\
\text { to the total number of words } \\
\text { ((connectors/total words) } \times 100) \text {. } \\
\text { Proverb score: result in proverb } \\
\text { interpretation }\end{array}$} & CF107 & 17 & 403 & 4.22 & 5.75 \\
\hline & CF108 & 13 & 482 & 2.70 & 5.00 \\
\hline & CF109 & 34 & 640 & 5.31 & 10.00 \\
\hline & CF110 & 59 & 1133 & 5.21 & 8.67 \\
\hline & CF112 & 21 & 506 & 4.15 & 7.33 \\
\hline & Mean & 20.20 & 481.20 & 3.72 & 5.98 \\
\hline & $\mathrm{SD}$ & 16.24 & 253.96 & 1.30 & 2.93 \\
\hline
\end{tabular}

by verbal IQ which correlated with total words (see below) and although vIQ was a not a significant covariate, its inclusion as a covariate in a subsequent ANOVA reduced the diagnosis effect so that it was clearly not significant (ANCOVA, $F=1.55$, df 1,19, $p=0.23)$.

\section{Connectors}

Schizophrenic patients produced fewer connectors than control subjects $(t=3.27$, df 20, $p<0.01$ ). Verbal IQ was a significant covariate (ANCOVA, $\mathrm{F}=6.99$, df $19,1, p<0.05$ ) of the number of connectors, however the diagnosis difference remained even when vIQ was included (diagnosis effect: $\mathrm{F}=5.35$, df 1,19, $p<0.05$ ) (Table 1).

The connector number calculated as a percentage of total words also indicated that patients produced relatively fewer connectors than control subjects (see Tables 2, 3 for mean values) 
Table 2 Schizophrenia (Pearson's r values reported)

\begin{tabular}{|c|c|c|c|c|}
\hline & Total_words & Connectors & Percent_connectors & Proverbs \\
\hline \multicolumn{5}{|l|}{$\begin{array}{l}\text { Correlations }^{\mathrm{a}} \\
\text { Total words }\end{array}$} \\
\hline Pearson correlation & 1 & $.977 * *$ & $.750 * *$ & $.613 *$ \\
\hline Sig. (2-tailed) & & .000 & .001 & .015 \\
\hline $\mathrm{N}$ & 15 & 15 & 15 & 15 \\
\hline \multicolumn{5}{|l|}{ Connectors } \\
\hline Pearson correlation & $.977 * *$ & 1 & $.856^{* *}$ & $.678 * *$ \\
\hline Sig. (2-tailed) & .000 & & .000 & .005 \\
\hline $\mathrm{N}$ & 15 & 15 & 15 & 15 \\
\hline \multicolumn{5}{|l|}{ Percent_connectors } \\
\hline Pearson correlation & $.750 * *$ & $.856^{* *}$ & 1 & $.796^{* *}$ \\
\hline Sig. (2-tailed) & .001 & .000 & & .000 \\
\hline $\mathrm{N}$ & 15 & 15 & 15 & 15 \\
\hline \multicolumn{5}{|l|}{ Proverbs } \\
\hline Pearson correlation & $.613^{*}$ & $.678 * *$ & $.796^{* *}$ & 1 \\
\hline Sig. (2-tailed) & .015 & .005 & .000 & \\
\hline $\mathrm{N}$ & 15 & 15 & 15 & 15 \\
\hline
\end{tabular}

** Uncorrected $p<0.01$ (2-tailed)

* Uncorrected $p<0.05$ (2-tailed)

${ }^{\text {a }}$ Group $=$ Schizophrenia

$(\mathrm{t}=4.39$, df $20, p<0.01)$. As may be expected, vIQ was also a significant covariate of this relative measure of connector density (ANCOVA, $\mathrm{F}=8.50$, df $1,19, p=0.01$ ). Yet the diagnosis difference remained significant $(\mathrm{F}=5.51$, df $1,19, p<0.05)$.

Proverbs

Schizophrenic patients scored lower than controls on the proverb interpretation test (see Tables 2, 3 for mean values) ( $t$ test (equal variance not assumed), $\mathrm{t}=7.35$, df $17.9, p<0.01$ ). Although the unequal variance limits the use of ANOVA, a post-hoc investigative ANCOVA suggested that verbal IQ was a significant covariate $(\mathrm{F}=13.63$, df $1,19, p<0.01)$ while the diagnostic difference remained strong $(\mathrm{F}=12.99$, df 1,19, $p<0.01)$ (Fig. 1).

\section{Correlation analyses}

The following measured variables were reciprocally positively correlated (Pearson's correlations at the $p \leq 0.01$, see Tables 2, 3) in patients: total words, total number of connectors, relative number of connectors (percentage), and proverb score. However, in controls the picture was clearly different (see Table 3); although total words and total number of connectors were positively correlated (Spearman's rho $=0.75, p=0.05$ ), total words was significantly negatively correlated with both percentage connectors (Spearman's rho $=-0.93, p<0.01$ ) and proverb interpretation (Spearman's rho $=-0.85, p<0.05$ ). The inverse relationships between patients and controls resulted in a significant difference in regression lines between the diagnostic groups for the total words: percentage connectors regression $(\mathrm{F}=25.6$, 
Table 3 Controls (Spearman's rho values reported):

\begin{tabular}{|c|c|c|c|c|}
\hline & Total_words & Connectors & Percent_connectors & Proverbs \\
\hline \multicolumn{5}{|l|}{$\begin{array}{l}\text { Correlations }^{\mathrm{a}} \\
\text { Spearman's rho }\end{array}$} \\
\hline \multicolumn{5}{|l|}{ Total_words } \\
\hline Correlation coefficient & 1.000 & .750 & $-.929^{* *}$ & $-.850^{*}$ \\
\hline Sig. (2-tailed) & & .052 & .003 & .015 \\
\hline $\mathrm{N}$ & 7 & 7 & 7 & 7 \\
\hline \multicolumn{5}{|l|}{ Connectors } \\
\hline Correlation coefficient & .750 & 1.000 & -.536 & -.472 \\
\hline Sig. (2-tailed) & .052 & & .215 & .284 \\
\hline $\mathrm{N}$ & 7 & 7 & 7 & 7 \\
\hline \multicolumn{5}{|l|}{ Percent_connectors } \\
\hline Correlation coefficient & $-.929 * *$ & -.536 & 1.000 & $.756^{*}$ \\
\hline Sig. (2-tailed) & .003 & .215 & & .049 \\
\hline $\mathrm{N}$ & 7 & 7 & 7 & 7 \\
\hline \multicolumn{5}{|l|}{ Proverbs } \\
\hline Correlation coefficient & $-.850^{*}$ & -.472 & $.756^{*}$ & 1.000 \\
\hline Sig. (2-tailed) & .015 & .284 & .049 & \\
\hline $\mathrm{N}$ & 7 & 7 & 7 & 7 \\
\hline
\end{tabular}

** Uncorrected $p<0.01$ (2-tailed)

* Uncorrected $p<0.05$ (2-tailed)

a Group $=$ Control

Fig. 1 Proverbs related to connectors. Positive correlations are found for both diagnostic groups

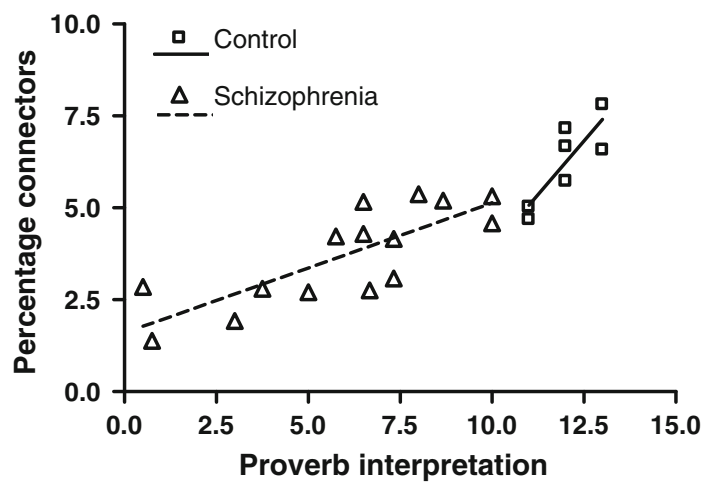

$p<0.01)$ and the total words: proverb score regression $(\mathrm{F}=6.1, p<0.05)$ (statistical analysis compares regression lines using ANCOVA based method (see Zar 1999) in GraphPad Prism)—see Figs. 2 and 3.

Of the demographic variables, verbal IQ was significantly positively correlated with full IQ (as described above) and with connectors (total: Pearson's $\mathrm{r}=0.49, p<0.05$ ) and percentage: Pearson's $r=0.72, p<0.01$ ) and proverb score (Pearson's $r=0.69, p<$ 0.01 ), but not with total number of words.

Within patients, the measured variables: total words, total number of connectors, percent connectors, and proverb score were not correlated with positive or negative symptoms (as 
Fig. 2 Total discourse output (total words) and relative number of connectors (percentage connectors). Regression lines are significantly different; $p<0.01$

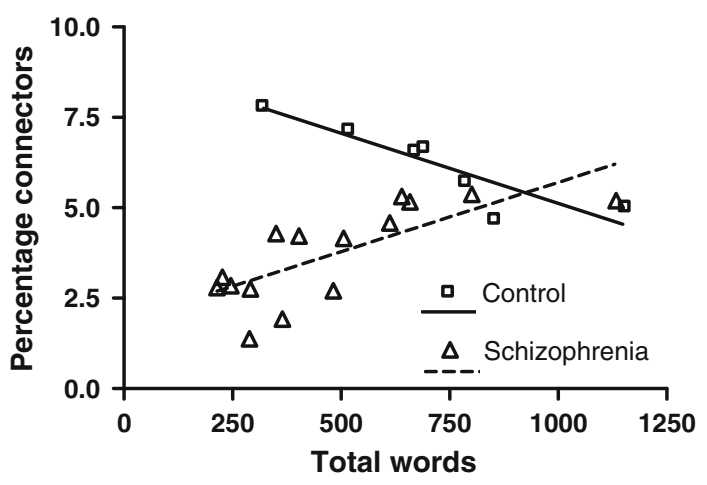

Fig. 3 Total discourse output (total words) and proverb interpretation score. Regression lines are significantly different; $p<0.05$

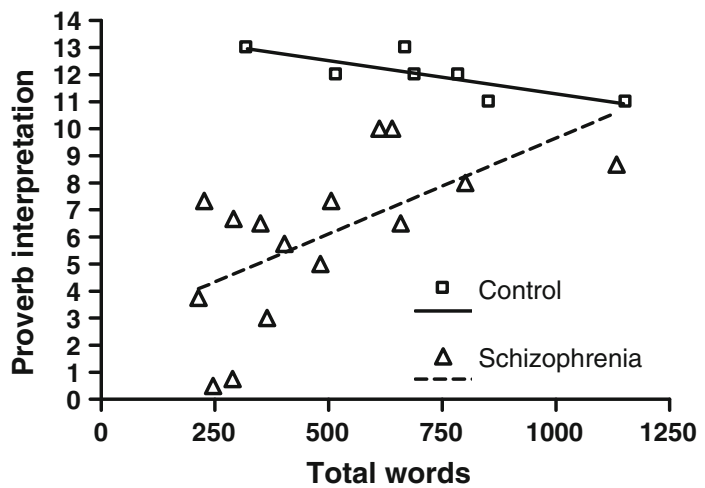

measured by the positive and negative symptom scale (PANSS)) or with medication. However, there were positive correlations between age of onset and total words (Pearson's $\mathrm{r}=0.51, p=$ $0.05)$, number of connectors $(\mathrm{r}=0.58, p<0.05)$, percentage connectors $(\mathrm{r}=0.62, p<$ $0.05)$, and at trend level with proverb score $(\mathrm{r}=0.49, p=0.07)$.

\section{Discussion}

Patients with schizophrenia show a less effective use of connectors than control subjects as well as a worse performance in proverb comprehension than control comparison subjects. Such deficits were hypothesized and it was further hypothesized that pragmatic ability in comprehension is related to pragmatic ability for production so that these would show a similar pattern of deficit in schizophrenia. For both connectors and proverbs the mean scores were lower while the variation (standard deviation) was higher for patients compared with controls. We therefore suggest that the two measures reflect a common underlying pragmatic ability. The results reinforce the idea that pragmatic processes such as those described by relevance theory and implicatures are affected to a similar degree in schizophrenia. For patients the results show a clear positive linear correlation between the two parameters. The relationship between connectors and proverb interpretation suggests an underlying pragmatic ability that is a common root for both productive and receptive aspects.

The relationship between total number of connectors and proverb interpretation was not clear in the control group alone, where no statistical correlation was found. This may be partly 
due to a ceiling effect causing low variation of proverb comprehension in control subjects who often exhibit optimal understanding and tend to score at the maximum. However, it is striking that a significant, positive relationship between the relative number of connectors ("percentage connectors") and proverb interpretation was detected within the control group (it was also detected in the patients separately). Therefore, where a control subject uses relatively few connectors on average, he or she also tends to interpret proverbs with less success. It is possible that the relative measure of connectors provides a better index of pragmatic ability because it takes account of variation in the total number of words generated which may, itself, be influenced by multiple additional factors such as overall verbal IQ. Indeed, the total number of connectors was positively correlated with verbal IQ in controls whereas the percentage connectors was not.

It is probably not surprising that IQ measures tended to be positively correlated with pragmatic language scores. However, it is interesting that significant diagnostic effects on the total number and relative number of connectors (and proverb scores) were found even when statistically controlling for verbal IQ. This suggests that pragmatic aspects of language in the form of connectors and proverb interpretation may be particularly vulnerable to schizophrenic disorder even compared with other verbal ability.

It is notable that the effective use of connectors is not simply a result of greater word production. Although the total number of connectors is, predictably, increased when the total output of words is greater, for both patients and controls, there is a striking diagnosisdependent difference in the form of relationship between total words and the percentage connectors, as well as the proverb interpretation score. While the controls generally demonstrate greater competence overall, the highest relative number of connectors and the best proverb scores are achieved by those producing a lower total word output. Whereas, in schizophrenia, the more loquacious subjects are also those who produce the higher relative number of connectors and achieve better proverb interpretation. This interesting reversal includes a region of overlap (see Figs. 2, 3) where the more able patients function at a similar level to the less able controls (eg. high total words and a low-ish normal pragmatic ability), as is often seen for many neuropsychological and behavioural (and neuroanatomical) measures in schizophrenia. However, the difference hints at different strategies in the two groups: for patients higher pragmatic function is linked to greater word production, whereas even better pragmatic ability, as seen in controls, appears to be linked to more "efficient" discourse, producing fewer words overall.

The present results, for the proverb task, are similar to those of Brüne and Bodenstein (2005), who obtained similar mean scores using the same scale and test paradigm (Brüne and Bodenstein reported an average of 6.6 with an SD of 5.0 for schizophrenic patients, and 13.2 (SD 1.1) for controls). (Slightly higher variation for patients in that study may be due to the authors' inclusion of more proverbs for interpretation). Therefore, we infer that our results are consistent with existing data.

The implication of the positive correlations between the pragmatic language measures and the age of onset is that later onset preserves more effective word production and use of connectors in speech. This is consistent with the general finding that later onset tends to be associated with less severe disease course and is also more common in females who tend to develop mature verbal ability earlier than males.

\section{Study Limitations}

A consensus has not been reached on a reliable method to quantify proverb interpretation. Although the use of proverbs has been criticised as a diagnostic tool (Andreasen 1977), 
several investigators have refined the techniques to assess this trait for neuropsychological research (Barth and Küfferle 2001; Brüne 2005; Holm-Hadulla 1991). Audio recordings also present a challenge as some words or parts of speech are inaudible and there may be pragmatic elements which are visual, unformulated, and therefore inaccessible to the analyst. Furthermore, patients more frequently neglect their articulation, and some individuals tend to repeat some words, like "and", "but" or "because", in a mechanical way, so that the pragmatic value is not clear. It may be desirable to conduct further work on a larger sample size. However, this relatively small study has sufficient power to identify clear statistical diagnostic differences and correlations. In particular, a larger control group may enable subject matching, but within the time and resource constraints of this study it was felt that the control sample was sufficient to represent the typical healthy pragmatic ability at the upper end of the range. As discussed above, the proverb interpretation encountered a ceiling effect for control subjects whereas it was of greater interest to examine a wider range of pragmatic competence by including more patients with schizophrenia, which was the focus of this study.

\section{Further Observations}

More often with controls than with patients, the subjects expressed a metalinguistic concern; they were worried about whether or not they had said enough. For example: "Is that ok?", "Should I stop here?", "How long do you want me to talk for?" "Is that sufficient, or would you like me to talk more?" These illustrate a worry related to the situation of the interview, and assume that the interviewer is aware of the artificiality of this situation as well. Such metalinguistic features tend to be linked with the awareness of the interlocutor's thoughts and feelings. It may not be coincidence that these elements appeared to occur more frequently in controls than in patients. However, they were not a common enough feature to be quantified.

In addition, one potentially interesting observation is that controls tended to make links between proverbs, but this never happened with schizophrenic patients. Comments such as "That's awfully similar to the last one actually" or "I think it's very similar to the last proverb in many ways" were noted several times. These co-textual mentions occurred in 5 out of 7 control subjects, while they were not observed on any single occasion in patients. It would be interesting to find a framework in which these annex observations might be taken into account for pragmatic assessment.

\section{Conclusion}

In the present study, it was suggested that different types of pragmatic assessment would reveal similar impairment of underlying pragmatic function in patients with schizophrenia. The results of the present study suggest that (i) schizophrenia is a condition that limits pragmatic capacities, and (ii) this affects both comprehension and production. Furthermore, high verbal IQ was associated with greater total discourse output (word number), but pragmatic ability was related differently to total output in patients and controls: patients with better pragmatic scores generated more total output, whereas control subjects with better pragmatic ability tended to be more efficient, using fewer words in total. For future studies, more complex experimental paradigms may facilitate exploration of the hierarchy of levels of pragmatics-Happé (1993) uses relevance theory to show that indeed there is a hierarchy of levels. Additional research on this subject may also consider physiological causes, develop- 
mental time course and the relationship to other forms of language abnormality in psychosis, including altered semantic memory.

\section{References}

Abu-Akel, A. (1999). Impaired theory of mind in schizophrenia. Pragmatics and Cognition, 7, 247-282.

Abu-Akel, A. (2003). A neurobiological mapping of theory of mind. Brain Research Reviews, 43, 29-40.

Andreasen, N. C. (1977). Reliability and validity of proverb interpretation to assess mental status. Comparative Psychiatry, 18, 465-472.

Anselmetti, S., Bechi, M., Bosia, M., Quarticelli, C., Ermoli, E., Smeraldi, E., et al. (2009). Theory of mind impairment in patients affected by schizophrenia and in their parents. Schizophrenia Research, 115, 278285.

Barth, A., \& Küfferle, B. (2001). Die Entwicklung eines Sprichwort-tests zur Erfassung konkretistischer Denkstfrungen bei schizophrenen Patienten. Nervenarzt, 72, 853-858.

Bokat, C., \& Goldberg, T. (2003). Letter and category fluency in schizophrenic patients: A meta-analysis. Schizophrenia Research, 64(1), 73-78.

Bora, E., Yucel, M., \& Pantelis, C. (2009). Theory of mind impairment in schizophrenia: Meta-analysis. Schizophrenia Research, 109, 1-9.

Brüne, M., \& Bodenstein, L. (2005). Proverb comprehension reconsidered-Theory of mind and the pragmatic use of language in schizophrenia. Schizophrenia Research, 75, 233-239.

Brüne, M. (2005). "Theory of Mind" in Schizophrenia: A review of the literature. Schizophrenia Bulletin, $30(1), 21-42$.

Corcoran, R., Mercer, G., \& Frith, C. (1995). Schizophrenia, symptomatology and social inference: Investigating 'theory of mind' in people with schizophrenia. Schizophrenia Research, 17(1), 5-13.

Corcoran, R., \& Frith, C. (2003). Autobiographical memory and theory of mind: Evidence of a relationship in schizophrenia. Psychological Medicine, 33, 897-905.

Corcoran, R. (2000). Theory of mind in other clinical conditions: Is a selective 'theory of mind' deficit exclusive to autism? In S. Baron-Cohen, H. Tager-Flusberg, \& D. J. Cohen (Eds.), Understanding Other Minds (2nd ed., pp. 391-421). Oxford: Oxford University Press.

Cram, D., \& Hedley, P. (2005). Pronouns and procedural meaning: The relevance of spaghetti code and paranoid delusion. Oxford Working Papers in Linguistics, Philology and Phonetics, 10, 187-210.

Cummings, L. (2009). Clinical Pragmatics. Cambridge: Cambridge University Press.

Frith, C., \& Corcoran, R. (1996). Exploring 'theory of mind' in people with schizophrenia. Psychological Medicine, 26, 521-530.

Grice, H. P. (1975) Logic and conversation. In P. Cole \& J. L. Morgan (Eds.) Syntax and Semantics (Vol. 3, pp. 41-58). Speech Acts New York, NY Academic Press. Reproduced in S. Davis (Eds.) 1991, Pragmatics: A Reader (pp. 305-315). Oxford: Oxford University Press.

Happé, Francesca. (1993). Communicative competence and theory of mind in autism: A test of relevance theory. Cognition, 48, 101-119.

Harrington, L., Siegert, R., \& McClure, J. (2005). Theory of mind in schizophrenia: A critical review. Cognitive Neuropsychiatry, 10, 249-286.

Holm-Hadulla, R. (1991). Zur Struktur schizophrenen Denkens und Sprechens-eine mittels Sprichwortinterpretationen empirisch fundierte psychopathologische Perspektive. Schizophrenie und Sprache, 61-70. http://www.holm-hadulla.de/pages/files/Holm-Hadulla_peer-reviewed.pdf.

Hopper, R., Knapp, M. L., \& Scott, L. (1981). Couples' personal idioms: Exploring intimate talk. Journal of Communication, 31(1), 23-33.

Huang, Y. (2006). Pragmatics. Oxford: Oxford University Press.

Langdon, R., Coltheart, M., Ward, P., \& Catts, S. (2002). Disturbed communication in schizophrenia: The role of poor pragmatics and poor mind-reading. Psychological Medicine, 32, 1273-1284.

Mitchley, N., Barber, J., Gray, J., D. Brooks, N., \& Livingston, M. (1998). Comprehension of irony in Schizophrenia. Cognitive Neuropsychiatry,3(2), 127-138.

Paulsen, J., \& Romeroa Ramon, C. A. (1996). Impairment of the semantic network in schizophrenia. Psychiatry Research, 63, 109-121.

Pickup, G., \& Frith, C. (2001). Theory of mind impairments in schizophrenia: Symptomatology, severity and specificity. Psychological Medicine, 31, 207-220.

Rossell, S. (2006). Category fluency performance in patients with schizophrenia and bipolar disorder: The influence of affective categories. Schizophrenia Research, 82, 135-138.

Sperber, D., \& Wilson, D. (1986, 1995). Relevance: Communication and cognition. Oxford: Blackwell. 
Sperber, D., \& Wilson, D. (2002). Pragmatics, modularity and mind-reading. Mind and Language, 17, 3-23.

Sprong, M., Schothorst, P., \& Vos, E. (2007). Theory of mind in Schizophrenia: Meta-analysis. The British Journal of Psychiatry, 191, 5-13.

Zar, J. (1999). Biostatistical analysis (4th Edn). New Jersey: Prentice-Hall. 